\title{
Primary dapsone resistance in Bamako and Chingleput: final report; THELEP
}

\author{
Subcommittee on Clinical Trials of the Chemotherapy of Leprosy. \\ (THELEP) Scientific Working Group of the UNDP/World \\ Bank/WHO Special Programme for Research and Training in \\ Tropical Diseases
}

Accepted for publication 13 March 1987

\begin{abstract}
Summary Approximately $37 \%$ of the 131 patients with lepromatous leprosy admitted into the THELEP controlled clinical trials in Bamako and Chingleput, whose Mycohacterium leprac obtained from pretreatment biopsy specimens could be tested in mice, have been found to harbour dapsone-resistant organisms, and are thought to represent instances of primary resistance to dapsone. The majority of these patients harboured strains of a low degree of resistance, one-fifth of these patients harboured organisms of an intermediate resistance, and no patient was found to harbour $M$. leprae of a high degree of resistance. No relationships were discerned between patient age, number of $M$. leprae, or disease classification on one hand, and primary resistance to dapsone on the other.
\end{abstract}

Members of the THELEP Clinical Trials Subcommittee are:

Dr M Christian, Schieffelin Leprosy Research and Training Centre, Karigiri, South India,

Dr MJ Colston, National Institute for Medical Research, London, UK,

Dr GA Ellard, National Institute for Medical Research, London, UK,

Dr CAP Ferracci, Institut Marchoux, Bamako, Mali,

Dr JH Grosset, Faculte de Medicine Pitie-Salpetriere, Paris, France,

Dr G Grossetete, Institut Marchoux, Bamako, Mali,

Dr CGS Iyer*, Central Leprosy Teaching and Research Institute, Chingleput, South India,

Dr Ji Baohong, World Health Organization, Geneva, Switzerland,

Dr Kyaw Lwin, Ministry of Health, Rangoon, Burma,

Dr DL Leiker, Royal Tropical Institute, Amsterdam, the Netherlands,

Dr L Levy, Hebrew University-Hadassah Medical School, Jerusalem, Israel,

Dr SK Noordeen, World Health Organization, Geneva, Switzerland,

Dr SR Pattyn, Prince Leopold Institute for Tropical Medicine, Antwerp, Belgium,

Dr JMH Pearson, Dhoolpet Leprosy Research Centre, Hyderabad, India,

* Deceased 
Dr RJW Rees, National Institute for Medical Research, London, UK,

Dr H Sansarricq, World Health Organization, Geneva, Switzerland,

Dr PS Seshadri, Central Leprosy Teaching and Research Institute, Chingleput, South India,

Dr JK Seydel, Borstel Research Institute, Borstel, Federal Republic of Germany, Dr CC Shepard*, Centers for Disease Control, Atlanta, Georgia, USA,

Dr MFR Waters, Hospital for Tropical Diseases, London, UK.

Also participating in this study were Drs RD McDermott and GRF Hilson, Department of Medical Microbiology, St George's Hospital Medical School, London, UK. Mr JL Duppenthaler, World Health Organization, Geneva, Switzerland, provided statistical consultation throughout the trials, and Mrs M Anker, World Health Organization, performed the statistical analyses.

This report was prepared by L Levy, M Anker and GA Ellard.

\section{Introduction}

Because of the apparently increasing prevalence of primary resistance to dapsone that has been observed in the course of formal surveys, this problem has received increased attention of late. Two surveys, of which a preliminary report has already been published, ${ }^{1}$ were carried out as one facet of the controlled clinical trials of combined chemotherapy mounted by THELEP (the Scientific Working Group on the Chemotherapy of Leprosy of the UNDP/World Bank/WHO Special Programme for Research and Training in Tropical Diseases) among previously untreated patients with lepromatous leprosy in Bamako, Mali, and Chingleput, South India. ${ }^{2}$

The preliminary report ${ }^{1}$ presented data based on examination of the Mycobacterium leprae isolated from the pretreatment biopsy specimens of the first 112 patients recruited into the two trials - 45 in Bamako and 67 in Chingleput. Thirty-five \% of the Bamako patients and $37.5 \%$ of the Chingleput patients, the susceptibility of whose organisms could be determined, were found to harbour dapsone-resistant $M$. leprae. The last patients recruited into the two trials were admitted in the latter part of 1983 , so that complete information on the susceptibility to dapsone of the M. leprae of 215 patients-99 in Bamako and 116 in Chingleput-is now available.

\section{Materials and methods}

The patients recruited into the two trials, and the methods employed in the trials, including those employed to test the susceptibility to dapsone of the pretreatment isolates of $M$. leprae, are those already described. ${ }^{1,2}$ In brief, patients with LL, LI

* Deceased 
or $\mathrm{BL}^{*}$ leprosy were recruited who denied prior treatment, and in whose urine no dapsone could be detected. Before treatment was begun, biopsy-specimens were obtained from skin lesions and shipped by air on wet ice to London. In the Department of Medical Microbiology, St George's Hospital Medical School, the specimens were homogenized, and $M$. leprae were recovered, counted, diluted, so as to provide an inoculum of $10^{4}$ organisms per foot-pad, and inoculated into the right-hind foot-pads of CD-1 mice. Groups of 8 mice were administered a drugfree diet, and groups of 5-7 mice were fed diets into which had been incorporated dapsone in concentrations of $0.0001,0.001$ or $0.01 \mathrm{~g}$ per $100 \mathrm{~g}$ diet. Approximately 6 months after inoculation, several control mice (those administered the drug-free diet) were sacrificed, and $M$. leprae were harvested from the inoculated foot-pads. If $M$. leprae were found not to have multiplied after 6 months, harvests were again performed from control mice after 9 months. Similarly, if $M$. leprae were found not to have multiplied after 9 months, harvests were performed from additional control mice after 12 months. When the organisms were noted to have multiplied in control mice, harvests were performed from all surviving treated mice.

Viable $M$. leprae were judged to be present if organisms were found to have multiplied to a level $\geq 10^{5}$ per foot-pad. $M$. leprae were determined to be resistant to dapsone in a given concentration if they multiplied in at least one mouse administered dapsone in that concentration. The $M$. leprae were considered to be susceptible to dapsone if two criteria were met: 1 , the organisms did not multiply in a single mouse administered dapsone in any concentration; and 2, comparison of the numbers of untreated mice showing multiplication or no multiplication with those of mice administered dapsone in the smallest concentration $(0.0001 \mathrm{~g}$ per $100 \mathrm{~g}$ diet) by means of the Fisher one-tailed test ${ }^{4}$ yielded a value for $P \leq 0.05$ (i.e. the probability that the two sets of results had been drawn from the same population of results was no larger than 1 in 20). Finally, when the organisms did not multiply in a single treated mouse, but multiplied in so few untreated mice that the comparison described in criterion 2 (v.s.) yielded a value for $P>0.05$, the susceptibility of that patient-strain of $M$. leprae to dapsone could not be determined.

Data were analysed by means of a number of statistical techniques. Nonparametric techniques were employed, because these may be applied to data that are not distributed normally. The techniques employed were $e^{4-6}: 1$, the $\chi^{2}$ and Fisher exact probability techniques for comparison of frequencies in contingency tables (e.g. the frequency of the histopathological classification LI among patients with susceptible and resistant strains); 2 , the Mann-Whitney $U$ test, for comparison of two independent groups according to a variable, the measurement scale of which is at least ordinal (e.g. the pretreatment bacteriological index (BI) ${ }^{7}$

* The Ridley-Jopling classification of leprosy, a system based on clinical, histopathological and other criteria, employs the following terminology: BL, borderline-lepromatous; $\mathrm{LI}$ (or $\mathrm{LL}_{\mathrm{s}}$ ), subpolar lepromatous leprosy; $L L$ (or $\mathrm{LL}_{\mathrm{p}}$ ), polar lepromatous leprosy ${ }^{3}$ 
of patients harbouring dapsone-susceptible or -resistant strains of $M$. leprae); and 3 , the one-sample-runs test, to examine the order in which events (e.g. the admission of patients harbouring dapsone-resistant organisms) occurred.

\section{Results}

\section{Prevalence of dapsone resistance}

It was possible to assess the susceptibility to dapsone of the $M$. leprae recovered from 131 of the 215 biopsy-specimens obtained before treatment was begun. The $M$. leprae recovered from 82 specimens judged to contain dapsone-susceptible organisms multiplied to a level $\geq 10^{5}$ in a large proportion of control mice, and in no mouse administered dapsone in any concentration. Thirty-seven of $64(58 \%)$ Bamako patients and 45 of $67(67 \%)$ Chingleput patients were shown to harbour dapsone-susceptible organisms.

$M$. leprae recovered from 49 specimens were judged to be dapsone-resistant. The organisms recovered from 39 specimens multiplied to a level $\geq 10^{5} \mathrm{M}$. leprae per foot-pad in at least one mouse administered dapsone in the smallest concentration, but failed to multiply in a single mouse administered dapsone in a larger concentration. These pretreatment specimens represent the patients whose strains of $M$. leprae demonstrated a low degree of resistance to dapsone. Organisms from 10 specimens demonstrated an intermediate degree of resistance to dapsone, multiplying to a level $\geq 10^{5}$ per foot-pad in mice administered dapsone in the smallest concentration, and in at least one mouse administered the drug in the concentration of $0.001 \mathrm{~g}$ per $100 \mathrm{~g}$ diet. No specimen yielded $M$. leprae capable of multiplying in mice administered dapsone in the concentration of 0.01 $\mathrm{g}$ per $100 \mathrm{~g}$ diet (the definition of strains demonstrating a high degree of resistance to dapsone).

The results of study of the $M$. leprae recovered from the pretreatment biopsy specimens of 215 patients admitted to the THELEP trials in Bamako and Chingleput are summarized in Table 1 . Considering the 131 patients in both centres, of whose $M$. leprae the susceptibility to dapsone could be determined, the prevalence of primary dapsone resistance was found to be 27 of $64(42 \cdot 2 \%)$ Bamako patients, and 22 of $67(32.8 \%)$ Chingleput patients; these estimates of prevalence did not differ significantly between the two treatment centres $(P=0 \cdot 27)$, nor from the results reported earlier. ${ }^{1}$ It is also apparent that the majority of the 49 patients harbouring dapsone-resistant $M$. leprae ( 21 of 27 $(78 \%)$ in Bamako; 18 of $22(82 \%)$ in Chingleput) harboured organisms exhibiting only a low degree of resistance to dapsone. As shown in Table 2, the proportion of patients harbouring dapsone-resistant $M$. leprae did not differ significantly among the regimens* $(P=0.13$ for Bamako, 0.34 for Chingleput).

* Patients were allocated among six treatment-groups, three in each centre; however, one of the 
Table 1. Distribution of dapsone-resistant patients and degree of resistance between centres

\begin{tabular}{lcc}
\hline Category of patient & $\begin{array}{c}\text { Bamako } \\
\text { (No. of patients) }\end{array}$ & $\begin{array}{c}\text { Chingleput } \\
\text { (No. of patients) }\end{array}$ \\
\hline Total & 99 & 116 \\
Susceptible & 37 & 45 \\
Resistant & 27 & 22 \\
$0 \cdot 0001 \mathrm{~g} \%$ & 21 & 18 \\
$0 \cdot 001 \mathrm{~g} \%$ & 6 & 4 \\
$0.01 \mathrm{~g} \%$ & 0 & 0 \\
Susceptibility & 35 & 49 \\
$\quad$ undeterminable & & \\
\hline
\end{tabular}

The frequency of resistant patients did not differ significantly between centres.

Table 2. Distribution of dapsone-resistant patients among regimens

\begin{tabular}{|c|c|c|c|c|c|}
\hline \multirow[b]{3}{*}{ Category of patient } & \multicolumn{5}{|c|}{ Regimen* } \\
\hline & \multicolumn{3}{|c|}{$\begin{array}{l}\text { Bamako } \\
\text { (No. of } \\
\text { patients) }\end{array}$} & \multicolumn{2}{|c|}{$\begin{array}{c}\text { Chinglepu } \\
\text { (No. of } \\
\text { patients) }\end{array}$} \\
\hline & $\mathrm{A}_{2}$ & $\mathrm{C}$ & $\mathrm{E}_{2}$ & $A_{1}$ & $C \quad D_{1}$ \\
\hline Total & 12 & 44 & 43 & 39 & $39 \quad 38$ \\
\hline Susceptible & 7 & 10 & 20 & 18 & $11 \quad 16$ \\
\hline Resistant & 3 & 14 & 10 & 8 & 95 \\
\hline $\begin{array}{l}\text { Susceptibility } \\
\text { undeterminable }\end{array}$ & 2 & 20 & 13 & 13 & $19 \quad 17$ \\
\hline
\end{tabular}

five regimens (regimen $\mathrm{C}$ ) was employed in both centres. The regimens were, in Bamako, $\mathrm{A}_{2}$ : rifampicin, protionamide and dapsone, each in a daily dose of 600,500 , and $100 \mathrm{mg}$, respectively, for two years; C: rifampicin, in a single initial dose of $1,500 \mathrm{mg}$, and dapsone, $100 \mathrm{mg}$ daily for two years; $\mathrm{E}_{2}$ : rifampicin, $900 \mathrm{mg}$ once weekly, and protionamide, $500 \mathrm{mg}$ daily for the first three months, together with dapsone, $100 \mathrm{mg}$ daily for two years; and in Chingleput, $\mathrm{A}_{1}$ : rifampicin, clofazimine and dapsone, each in a daily dose of 600,100 , and $100 \mathrm{mg}$, respectively, for two years; C: as for Bamako; $D_{1}$ : rifampicin, in a single initial dose of $1,500 \mathrm{mg}$, clofazimine, in a daily dose of 100 $\mathrm{mg}$ for the first three months, and dapsone, $100 \mathrm{mg}$ daily for two years ${ }^{2}$. 
Table 3. Median ages of patients harbouring susceptible, dapsone-resistant, and undeterminable strains of $M$. leprae

\begin{tabular}{lcc}
\hline & \multicolumn{2}{c}{ Median age (years) } \\
\cline { 2 - 3 } $\begin{array}{l}\text { Category of } \\
\text { patient strain }\end{array}$ & Bamako & Chingleput \\
\hline Total & 25 & 29 \\
Susceptible & 25 & 25 \\
Resistant & 26 & 30 \\
Determinable & 26 & 27 \\
Undeterminable & 25 & 30 \\
\hline
\end{tabular}

Patient age did not differ significantly among categories.

As discussed in the earlier report, ${ }^{1}$ it is not absolutely possible to exclude the possibility that some of the patients judged to harbour primary dapsone-resistant $M$. leprae may actually have concealed previous treatment. However, such patients might be expected to be older on the average than those patients who had not been previously treated; they should have responded to the treatment and only subsequently relapsed. As shown in Table 3, the ages of the patients harbouring dapsone-resistant $M$. leprae did not differ significantly from those of the patients harbouring dapsone-susceptible organisms at either centre. The

Table 4. Age of the patients and dapsone resistance as functions of admission order

\begin{tabular}{lccccc}
\hline & \multicolumn{2}{c}{ Median age } & & \multicolumn{2}{c}{ Proportion resistant } \\
\cline { 2 - 3 } \cline { 5 - 6 } $\begin{array}{l}\text { Admission } \\
\text { quartile }\end{array}$ & Bamako & Chingleput & & Bamako & Chingleput \\
\hline 1 & 28 & 30 & & 0.20 & 0.20 \\
2 & 26 & 31 & & 0.44 & 0.42 \\
3 & 29 & 30 & & 0.53 & 0.41 \\
4 & 30 & 30 & & 0.50 & 0.33 \\
\hline
\end{tabular}

The proportion resistant (the proportion of patients harbouring dapsone-resistant $M$. leprae) is calculated as the fraction:

number resistant

number resistant + number susceptible;

those patients harbouring strains, the susceptibility of which could not be determined, are ignored. 
Table 5. Relationship of dapsone resistance to pretreatment patient characteristics

\begin{tabular}{lccccc}
\hline & \multicolumn{2}{c}{ Bamako } & & \multicolumn{2}{c}{ Chingleput } \\
\cline { 2 - 3 } \cline { 5 - 6 } $\begin{array}{l}\text { Pretreatment } \\
\text { characteristic }\end{array}$ & Resistant & Susceptible & & Resistant & Susceptible \\
\hline Median BI* & 4.7 & 4.5 & & 4.3 & 4.3 \\
Median LIB & 5.6 & 5.3 & & 5.4 & 5.5 \\
Median LAFBPG & 8.5 & 8.4 & & 8.7 & 8.3 \\
Proportion with & 0.74 & 0.78 & & 0.64 & 0.73 \\
$\quad$ CLINCLAS LI & & & & & 0.93 \\
Proportion with & 0.81 & 0.84 & & 0.95 & \\
$\quad$ HISTCLAS LI & & & & \\
\hline
\end{tabular}

No significant difference of any pretreatment characteristic was found between patients with dapsone-resistant and those with susceptible organisms in either centre.

* Abbreviations: BI, bacteriological index; LIB, logarithmic biopsy index; LAFBPG, logarithm 10 of the number of acid-fast bacilli per $g$ tissue; CLINCLAS, clinical classification according to Ridley and Jopling; HISTCLAS, histopathological classification according to Ridley and Jopling.

possibility that some previously treated patients who had relapsed with secondary resistance to dapsone had concealed the earlier treatment was also examined by considering patient age and the frequency of dapsone resistance as functions of admission order, on the assumption that, in order to increase the rate at which patients were recruited, admission criteria may have been relaxed in the course of the trials. In fact, as shown in Table 4, no relationships could be demonstrated between admission order, on the one hand, and age or resistance to dapsone on the other. Moreover, as shown in Table 5, no significant differences could be discerned between those patients of either centre harbouring susceptible $M$. leprae and those harbouring strains resistant to dapsone, with respect to $\mathrm{BI}$, logarithmic biopsy index (LIB), ${ }^{8} \operatorname{logarithm}_{10}$ of the number of acid-fast bacilli per $\mathrm{g}$ tissue (LAFBPG), ${ }^{9}$ and the proportions of patients classified clinically or histopathologically as LI.

\section{Susceptibility not determinable}

The susceptibility to dapsone could not be assessed of the strains of $M$. leprae obtained from the pretreatment biopsy-specimens of 35 of $99(35 \%)$ Bamako patients and 49 of $116(42 \%)$ Chingleput patients. None of these strains multiplied in dapsone-treated mice. The organisms recovered from 35 specimens failed to multiply to the level of $\geq 10^{5}$ in even a single untreated mouse. The $M$. leprae recovered from the remaining 49 specimens multiplied to a level $\geq 10^{5}$ in at 
Table 6. Strains of undeterminable susceptibility as a function of admission order

\begin{tabular}{lcc}
\hline & $\begin{array}{c}\text { Proportion } \\
\text { minable }\end{array}$ \\
\cline { 2 - 3 } $\begin{array}{l}\text { Admission } \\
\text { quartile }\end{array}$ & Bamako & Chingleput \\
\hline 1 & $0 \cdot 40$ & $0 \cdot 31$ \\
2 & $0 \cdot 36$ & $0 \cdot 59$ \\
3 & $0 \cdot 24$ & $0 \cdot 41$ \\
4 & $0 \cdot 42$ & $0 \cdot 30$ \\
\hline
\end{tabular}

A significant relationship was found between strains of undeterminable susceptibility and order of admission to Chingleput, whereas no significant relationship was found for Bamako.

least one untreated mouse, but multiplication was found to have occurred in so few control mice, that the failure of the organisms to multiply in dapsone-treated mice could not be taken as evidence of susceptibility to the drug. Thus, although the inocula prepared from these specimens contained viable $M$. leprae, the viable organisms must have represented so small a proportion of the total, that multiplication occurred in some mice but not in others.

Because the 84 patient strains of $M$. leprae of indeterminable susceptibility to dapsone represent two-fifths of all of the patients studied in the trials, an explanation for this phenomenon was sought. No significant difference could be demonstrated between the 84 patients harbouring these strains and those whose organisms were determined to be either susceptible or resistant to dapsone, according to centre $(P=0.30)$ or regimen $(P=0.12$ for Bamako, 0.36 for Chingleput). The failure of the organisms to multiply in large proportions of inoculated mice may be the result of some effective prior treatment; however, as shown in Table 3, no significant difference could be demonstrated between these and the remaining patients according to median age $(P=0 \cdot 46$ for Bamako, $0 \cdot 10$ for Chingleput). As shown by the data of Table 6, the proportion of Chingleput patients yielding $M$. leprae of undeterminable susceptibility was related to the order in which the patients were admitted to the trial $(P=0.05)$; however, the proportion of such patients appears to have diminished in successive admission quartiles, beginning with the second quartile, a result inconsistent with the possibility that admission criteria had been relaxed in order to increase the rate at which patients were recruited. No relationship between undeterminable suscepti- 
Table 7. Relationship of strains of undeterminable susceptibility to pretreatment patient characteristics

\begin{tabular}{|c|c|c|c|c|}
\hline \multirow{3}{*}{$\begin{array}{l}\text { Pretreatment } \\
\text { characteristic }\end{array}$} & \multicolumn{4}{|c|}{ Susceptibility } \\
\hline & \multicolumn{2}{|c|}{ Bamako } & \multicolumn{2}{|c|}{ Chingleput } \\
\hline & Determined & Undeterminable & Determined & Undeterminable \\
\hline Median BI* & $4 \cdot 7$ & $4 \cdot 5$ & $4 \cdot 3$ & $4 \cdot 3$ \\
\hline Median LIB & $5 \cdot 4$ & $5 \cdot 1$ & $5 \cdot 5$ & $5 \cdot 6$ \\
\hline Median LAFBPG & $8 \cdot 4$ & $8 \cdot 2$ & $8 \cdot 4$ & $8 \cdot 4$ \\
\hline $\begin{array}{l}\text { Proportion with } \\
\text { CLINCLAS LI }\end{array}$ & $0 \cdot 77$ & $0 \cdot 71$ & $0 \cdot 70$ & 0.67 \\
\hline $\begin{array}{l}\text { Proportion with } \\
\text { HISTCLAS LI }\end{array}$ & $0 \cdot 83$ & $0 \cdot 74$ & 0.94 & 0.98 \\
\hline
\end{tabular}

The LIBs for Bamako patients harbouring M. leprae, the susceptibility of which could be determined, and those harbouring organisms of undeterminable susceptibility differed significantly. No significant difference was found for any other pretreatment characteristic in either centre.

* Abbreviations as for Table 5.

bility and admission order could be discerned for admissions to the trial in Bamako.

As shown by the data of Table 7, patients at both centres whose pretreatment biopsy-specimens yielded organisms of undeterminable susceptibility did not differ from the remaining patients, whose specimens yielded dapsone-susceptible or -resistant organisms, with respect to the BI, the LAFBPG, and the proportions of patients classified clinically or histopathologically as LI. On the other hand, Bamako patients harbouring $M$. leprae of determinable susceptibility, but not Chingleput patients, differed from those harbouring organisms of undeterminable susceptibility with respect to the LIB $(P=0 \cdot 05)$.

\section{Discussion}

Analysis of the data on susceptibility to dapsone of 1.31 strains of $M$. leprae isolated from the pretreatment biopsy-specimens of the patients admitted to the THELEP controlled clinical trials of combined chemotherapy of lepromatous leprosy yielded estimates of the prevalence of primary dapsone-resistance of 42 per 100 patients at risk in Bamako and 33 per 100 patients in Chingleput. As was the case in the earlier analysis, ${ }^{1}$ no evidence was found to support the possibility that the high estimates of prevalence resulted from the inadvertent admission into the trials of previously treated patients who had relapsed because of secondary dapsone-resistance. 
Inspection of the available information with respect to the patients' pretreatment characteristics failed to reveal significant differences between those of patients harbouring dapsone-resistant and those harbouring dapsone-susceptible $M$. leprae, or between the pretreatment characteristics of patients whose pretreatment specimens yielded only small proportions of viable organisms and those whose specimens yielded large proportions of viable organisms. Thus, none of these characteristics, related to patient age, numbers of organisms or disease classification, could be employed to identify those patients who had been initially infected with strains of $M$. leprae resistant to dapsone.

The subject of primary resistance to dapsone has recently been carefully reviewed. ${ }^{10}$ The prevalence of primary resistance to dapsone measured in Bamako and Chingleput is consistent with the results of surveys of primary resistance carried out among smaller numbers of patients in several leprosyendemic areas, as is the finding that the majority of dapsone-resistant strains manifested a low degree of resistance.

\section{References}

I Subcommittee on clinical trials of the Chemotherapy of Leprosy (THELEP) Scientific Working Group of the UNDP/World Bank/WHO Special Programme for Research and Training in Tropical Diseases. Primary resistance to dapsone among untreated lepromatous patients in Bamako and Chingleput. Lepr Rev. 1983; 54: 177-83.

2 Subcommittee on clinical trials of the Chemotherapy of Leprosy (THELEP) Scientific Working Group of the UNDP/World Bank/WHO Special Programme for Research and Training in Tropical Diseases. THELEP controlled clinical trials in lepromatous leprosy. Lepr Rev, 1983; 54: $167-76$.

${ }^{3}$ Ridley DS, Jopling WH. Classification of leprosy according to immunity. A five-group system. Int J Lepr, 1966; 34: 255-73.

${ }^{4}$ Siegel, S. Non-parametric statistics for the behavioral sciences. McGraw-Hill Book Co., New York; 1956.

5 Gibbons JD. Non-parametric statistical inference. McGraw-Hill Book Co., New York; 1971.

${ }^{6}$ SAS User's Guide: Statistics. SAS Institute, Inc, Cary, NC, USA; 1982.

7 Ridley DS. Bacterial indices. In: Leprosy in theory and practice. Cochrane RG, Davey TF (eds), Baltimore: Williams \& Wilkins, 1964; pp. 620-2.

${ }^{8}$ Ridley DS, Hilson GRF. A logarithmic index of bacilli in biopsies. Int J Lepr, 1967; 35: 1846.

${ }^{9}$ Collaborative effort of the US Leprosy Panel (US-Japan Cooperative Medical Science Program) and the Leonard Wood Memorial. A statistical analysis of two chemotherapy trials in lepromatous leprosy. I. The response to therapy as measured by inoculation of mice. Amer $J$ Trop Med Hyg, 1978; 27: 1005-14.

10 Ji Baohong. Drug-resistance in leprosy - a review. Lepr Rev, 1985, 56: 265-78. 